\title{
Tolvaptan treatment in hyponatraemia due to chronic heart failure
}

Dr Jayadave Shakher, Consultant Diabetologist and Endocrinologist Birmingham Heartlands Hospital, Heart of England NHS Trust

Hyponatraemia is the commonest electrolyte disorder in hospitals and frequently encountered in patients with heart failure (HF). Elevated circulating levels of arginine vasopressin AVP correlate with disease severity with higher levels in decompensated HF. The activation of AVP from posterior pituitary is mediated through pressure sensitive baroreceptors by impaired cardiac output resulting in increased passive water reasorption in the kidneys with resultant hyponatraemia. This case illustrates decline in sodium level to $<120$ $\mathrm{mmol} / \mathrm{L}$ in HF patient despite fluid management and discontinuation of diuretic. A short-term use of Tolvaptan normalises the serum sodium (SNa) and subsequent reintroduction of diuretic without adverse outcome.

Tolvaptan, a V2 receptor antagonist is licensed for treatment of SIADH in Europe based on two RCTs, SALT 1 and SALT 2. In both trials, heart failure with hyponatraemia accounted for $33 \%$ and $29 \%$ respectively. Tolvaptan significantly increased the average daily AUC for the SNa concentration from baseline to study day 4 through day 30 compared to placebo.

\section{Case}

85 year old lady with known LVSD with ejection fraction of $50 \%$ was admitted with symptoms of heart failure and treated with intravenous diuretic. Though her symptoms improved, her $\mathrm{SNa}$ gradually declined despite stopping the diuretic. Biochemistry showed SNa 114 with S Osmolality $243 \mathrm{mosm} / \mathrm{kg}$, Urine Osmolality $678 \mathrm{mosm} / \mathrm{kg}$ and urine sodium of $<20$. She had "appropriate" ADH elevation due to HF as evidenced by raised UrOsm in the setting of low SOsm. Tolvaptan $15 \mathrm{mg}$ was started and SNa was $131 \mathrm{mmol} / \mathrm{L}$ on day 4 with reduction in weight. Tolvaptan was discontinued. Her diuretic was restarted on day 8 and her $\mathrm{SNa}$ remained in normal range.

\section{Discussion}

Tolvaptan offers additional spectrum in the management of HF to improve symptoms and correction of moderate to severe hyponatraemia in selected cases. (Note: not licensed for HF in Europe)

\section{Mechanism of action - Tolvaptan}

Orally active, potent, selective $\mathrm{V} 2$ receptor antagonist Blocks vasopressin-mediated insertion of aqauporin- 2 water channel proteins into the apical membrane of the collecting duct principal cells

Aquaretic effect:

- Increased urine volume

- Decreased urine osmolality

- Increased plasma sodium concentration

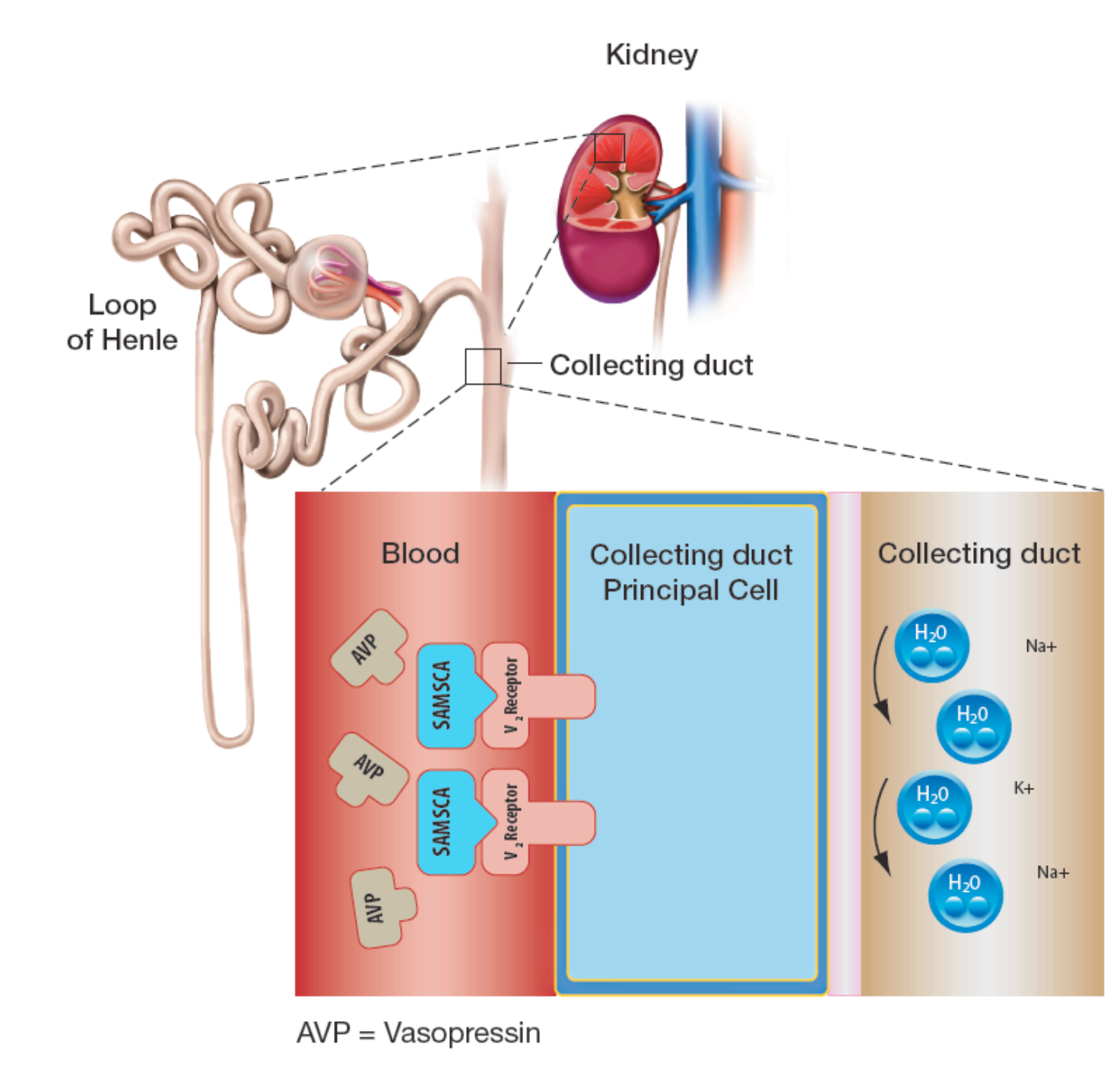

References:

Gheorghiade M, Gattis WA, O'Connor CM, et al. Effects of tolvaptan, a vasopressin antagonist, in patients

hospitalized with worsening heart failure: A randomized controlled trial. JAMA 2004; 291:1963-1971.

Konstam MA, Gheorghiade M, Burnett JC, et al. Effects of oral tolvaptan in patients hospitalized for worsening heart failure: The EVEREST outcome trial. JAMA 2007; 297:13191331.

Gheorghiade M, Konstam MA, Burnett, JC, et al. Short-term clinical effects of tolvaptan, an oral vasopressin antagonist, in patients hospitalized for heart failure: The EVEREST clinical status trials. JAMA 2007; 297:1332-1343. Schrier RW, Gross P, Gheorghiade M, et al for the SALT Investigators. Tolvaptan, a selective oral vasopressin V2receptor antagonist, for hyponatremia. N Engl J Med 2006; 355:2099-2112. 